\title{
Annealing effect on plastic flow in nanocrystalline CoCrFeMnNi high- entropy alloy: A nanomechanical analysis
}

\author{
Dong-Hyun Lee ${ }^{1}$, Jung-A Lee ${ }^{1}$, Yakai Zhao ${ }^{2}$, Zhaoping $\mathrm{Lu}^{3}$, Jin-Yoo $\mathrm{Suh}^{4}$, Ju-Young Kim ${ }^{5}$, \\ Upadrasta Ramamurty $^{6}$, Megumi Kawasaki ${ }^{7^{*}}$, Terence G. Langdon ${ }^{8}$, Jae-il Jang ${ }^{1 *}$ \\ ${ }^{1}$ Division of Materials Science and Engineering, Hanyang University, Seoul 04763, Republic of Korea \\ ${ }^{2}$ School of Materials Science and Engineering, Beijing Institute of Technology, Beijing 100081, People's \\ Republic of China \\ ${ }^{3}$ State Key Laboratory for Advance Metals and Materials, University of Science and Technology Beijing, \\ Beijing 10083, People's Republic of China \\ ${ }^{4}$ High Temperature Energy Materials Research Center, Korea Institute of Science and Technology, Seoul 02792, \\ Republic of Korea \\ ${ }^{5}$ School of Materials Science and Engineering, Ulsan National Institute of Science and Technology, Ulsan 44919, \\ Republic of Korea \\ ${ }^{6}$ Department of Materials Engineering, Indian Institute of Science, Bangalore 560012, India \\ ${ }^{7}$ School of Mechanical, Industrial \& Manufacturing Engineering, Oregon State University, Corvallis, OR 97331- \\ 6001, USA \\ ${ }^{8}$ Materials Research Group, Faculty of Engineering and the Environment, University of Southampton, \\ Southampton SO17 1BJ, UK
}

*Corresponding authors: jijang@ hanyang.ac.kr (J.-i. Jang), megumi.kawasaki@oregonstate.edu (M. Kawasaki)

\begin{abstract}
The influence of annealing on the constitutive stress-strain response of nanocrystalline (nc) CoCrFeMnNi high-entropy alloy (HEA) was investigated through a series of nanoindentation experiments using five different three-sided pyramidal indenters. The nc HEA, produced by high-pressure torsion (HPT), was subjected to annealing at $450{ }^{\circ} \mathrm{C}$ for 1 and $10 \mathrm{~h}$. Microstructural analysis using transmission electron microscopy (TEM) showed that three different nano-scale precipitates (NiMn-, FeCo-, and Co-rich phases) form in the primary single-phase matrix of nc HEA after annealing. The strain-dependent plastic flow response of nc HEA pre- and post-annealing was estimated using the indentation strain and constraint factor, revealing a significant strain softening in nc HEA, which becomes pronounced after annealing. TEM analysis of the deformed material underneath the indenter suggests that the plastic deformation aids in the dissolution of the annealing-induced intermetallic precipitates, which could be the mechanism for the pronounced softening. The dissolution mechanismwas
\end{abstract}


rationalized by the destabilization of precipitates during plastic deformation due to the increase in interface energy.

Keywords: high-entropy alloy, nanocrystalline metal, annealing effect, constitutive behavior 


\section{Introduction}

High-entropy alloys (HEAs), a new class of alloys defined for practical purposes as multicomponent alloys containing five or more elements in (near-)equal atomic percent, exhibit excellent mechanical properties over a wide range of temperatures (from elevated to cryogenic temperatures) [1-5]. Recently, it has been reported that those properties of HEAs can be further enhanced in a substantial manner through significant grain refinement, which can be easily achieved by severe plastic deformation (SPD) processing methods such as equal-channel angular pressing (ECAP) [6] and high-pressure torsion (HPT) [7]. It is possible to obtain nanocrystalline (nc) structure (average grain size, $d<100 \mathrm{~nm}$ [8-12]) in HEAs by subjecting them to HPT, which paves the way for exploiting synergy between HEA and nc alloys [13-16].

Recently, the issue of phase stability in HEAs during thermal treatments has been examined closely. It was observed that secondary phases can form in the HEA matrix, when they are annealed at the temperatures below $\sim 800{ }^{\circ} \mathrm{C}$ [14,17-20]. Since grain boundaries (GBs), especially non-equilibrium GBs in HPT processed materials, can serve as energetically favorable nucleation sites for the formation of new phases, the annealinginduced formation of new phases is expected to be accelerated in nc HEAs due to the large fraction of GBs in them. Indeed, Schuh et al. [14] reported that the decomposition of the primary matrix phase occurs in nc CoCrFeMnNi HEA in an accelerated manner (i.e., in 5 min at $450{ }^{\circ} \mathrm{C}$ ). They also observed a significant hardness increase and concomitant ductility loss in the nc HEA after annealing, which suggests that further investigation of the annealing effects may be required for elevated temperature applications of nc HEAs. Nevertheless, the annealing effect on the constitutive stress-strain behavior in the plastic regime (i.e., strain hardening or softening), which is crucial from the potential applications point of view, has not yet been studied systematically due to the difficulties in conventional mechanical testing. 
Vickers hardness tests provide only hardness corresponding to a specific single indentation strain, and tensile tests using micro-sized samples cannot represent the properties of only nc HEA since there is a marked gradient of microstructure in HPT processed disk samples and only the edge regions of the disks (that can hardly cover the whole gauge part of tensile specimen) show nc structures.

This difficulty may be overcome by performing nanoindentation tests that can estimate various mechanical properties by analyzing load-displacement $(P-h)$ curve recorded during the experiment [21-24]. In addition to being a simple and easy procedure, nanoindentation offers many advantages; the important one being that it requires only small volumes of test material. Thus, the tests have been extensively performed to explore mechanical properties of local microstructures [25,26]. Recently, Maier-Kiener et al. [27] performed such experiments on nc CoCrFeMnNi HEA annealed at various temperatures and investigated the influence of annealing on hardness and elastic modulus, from which the usefulness of the nanoindentation technique in the mechanical analysis of nc HEAs was established [27]. Additionally, such tests also allow for the exploration of the straindependent plastic flow behavior. There are two possible ways for achieving this goal. The first one is by using a spherical tip. Since this tip does not have a geometrical self-similarity, stress $\sigma$ and strain $\varepsilon$ underneath the indenter can increase with the applied load. Although it has a strong merit that elastic deformation and yield behavior can be obtained during indentation, plastic deformation at large strains cannot be achieved for the following two practical issues. (1) The depth to which spherical shape can be maintained is limited due to the limitation of the tip manufacturing process. (2) The widely used Hertz theory for the analysis of spherical indentation is developed on the assumption that the tip geometry is a "paraboloid of revolution" that can be considered as a "sphere" and hence is applicable only for shallow depths of penetration. Another way of $\sigma-\varepsilon$ estimation is using a series of sharp 
(typically, three-sided pyramidal) indenters having different indenter angles. Generally, sharper indenters induce larger elasto-plastic strains in the material [23,28-30], and indentations made with different angles lead to different levels of plastic strain, thereby allowing a systematic evaluation of the effects of the imposed strain.

Accordingly, here we explored the influence of the annealing on the strain-dependent plastic flow, and thus on the constitutive behavior of HPT processed nc CoCrFeMnNi through a series of nanoindentation experiments using five different three-sided pyramidal indenters having different values for the centerline-to-face angle, $\psi$. In addition, the tests under the identical conditions were also carried out on the coarse-grained (cg) HEA (i.e., ascast HEA) for comparison purposes. The results revealed that the nature of plastic flow in nc CoCrFeMnNi HEA is significantly affected by the annealing treatment.

\section{Experimental}

The equiatomic CoCrFeMnNi HEA examined in this work was prepared by arcmelting a mixture of pure metals (purity >99 wt.\%) in a Ti-gettered high-purity $\mathrm{Ar}$ atmosphere. The as-cast alloy was cut and electrical-discharge machined into $10 \mathrm{~mm}$ diameter, $0.8 \mathrm{~mm}$ thick disks. They were subjected to HPT at room temperature with a pressure of 6.0 GPa at $1 \mathrm{rpm}$ for a total of 2 turns. Fig. 1 shows the microstructures of the as-cast and HPT processed HEA samples. It is evident that HPT induces a substantial reduction in average grain size $d$ from $\sim 40 \mu \mathrm{m}$ to $\sim 40 \mathrm{~nm}$, which confirms earlier observations that HPT process can achieve significant grain refinement in the CoCrFeMnNi HEA [13-15]. Subsequent to HPT, some samples were subjected to annealing at $450{ }^{\circ} \mathrm{C}$ (at which hardness was found to be the maximum in the previous isochronal annealing study [14]) for 1 and $10 \mathrm{~h}$ (hereafter, designated HPT+1A and HPT+10A samples, respectively). For comparison purposes, the ascast sample was also examined, and thus there are four different samples that were tested 
here; as-cast, HPT, HPT+1A, and HPT+10A samples. The surfaces of the specimens were mechanically polished with fine SiC paper (grit number up to 2000) and subsequently with $0.05 \mu \mathrm{m}$ colloidal silica. Then, surfaces were vibration-polished for $24 \mathrm{~h}$ with $0.02 \mu \mathrm{m}$ colloidal silica using VibroMet 2 (Buehler, Lake Bluff, IL) to remove any possible surface damage induced during prior polishing.

Nanoindentation experiments were performed at the edge regions (within $0.3 \mathrm{~mm}$ from the edge) of the HPT disks using a Nanoindenter-XP (formerly MTS; now Keysight, Santa Rosa, CA) with five different three-sided pyramidal indenters having a centerline-toface angle $\psi$ of $35.3^{\circ}$ (cube-corner indenter), 50, $65.3^{\circ}$ (Berkovich indenter), $75^{\circ}$, and $85^{\circ}$. The samples were loaded to a maximum load, $P_{\max }$, of $100 \mathrm{mN}$ under constant strain rate, $(\mathrm{d} P / \mathrm{d} t) / P$ (where $P$ is indentation load), of $0.05 / \mathrm{s}$. More than 20 tests were performed for each condition. The hardness impressions were imaged using atomic force microscopy (AFM; XE-100, Park Systems, Suwon, Korea).

Annealing-induced microstructural changes were examined using transmission electron microscopy (TEM; Talos F200X, FEI Co., Hillsboro, OR). To prepare crosssectional TEM samples, focused ion beam (FIB) milling was performed with a Nova 200 NanoLab (FEI Co., Hillsboro, OR). During TEM analysis, element mapping was performed using energy dispersive X-ray spectroscopy (EDS).

\section{Results}

\subsection{Nanoindentation hardness variation}

Representative $P-h$ curves of the HPT, HPT $+1 \mathrm{~A}$, and HPT+10A samples recorded during nanoindentations with five indenters with different $\psi$ are displayed in Fig. 2a. Since the recorded displacement range for the as-cast sample differs significantly from those processed by HPT, its $P$ - $h$ plots are displayed separately in the inset of Fig. 2a. It is clear that 
the displacement at the peak load, $h_{\max }$, decreases with increasing $\psi$ for all four samples. Importantly, $h_{\max }$ for a given $\psi$ decreases in the sequence of as-cast, HPT, HPT+1A, and HPT+10A.

The ratio of the residual displacement after unloading, $h_{\mathrm{f}}$, to $h_{\max }$ is a useful indicator of the relative portion of the plastic deformation in the total elasto-plastic deformation that occurs during indentation. Fig. $2 \mathrm{~b}$ summarizes the variations in $h_{\mathrm{f}} / h_{\max }$ with $\psi$ for all samples. For a given $\psi$, the $h_{\mathrm{f}} / h_{\max }$ values obtained from three HPT processed samples are much lower than for the as-cast sample, implying that plasticity in the former is less pronounced than in the latter. Importantly, the value of $h_{\mathrm{f}} / h_{\max }$ increases with decreasing $\psi$, indicating that indeed a higher level of plasticity is produced with a sharper indenter. For $\psi=35.3^{\circ}$ (the sharpest tip), all four samples exhibit high $h_{\mathrm{f}} / h_{\max }$ values $(>\sim 0.9)$, indicating that the portion of plasticity is much higher than that of elasticity. For $\psi=85^{\circ}$ (the least sharp tip), a clear difference can be found between the as-cast and other samples; while the as-cast sample continues to show relatively high values of $h_{\mathrm{f}} / h_{\max }(\sim 0.74)$, the three HPT processed samples show very low $h_{\mathrm{f}} / h_{\max }$ values around 0.2 . These results suggest that, for $\psi=85^{\circ}$, the portion of elasticity is much higher than that of plasticity in HPT processed samples whereas plasticity still prevails over elasticity in the as-cast sample.

The most popular procedure for estimating the hardness by only nanoindentation $P$ - $h$ curve analysis is the Oliver-Pharr (O-P) method [21]. Nevertheless, here we did not adopt the $\mathrm{O}-\mathrm{P}$ method. This is mainly because the correlation constant $\beta$ in the O-P method (which relates stiffness $S$ to contact area $A$ and thus must be known for determining the area function and hence the hardness) is known only for the commonly used Berkovich indenter (as a constant of 1.034 [21]), but not for other indenters although some effort has been made [31].

To overcome this difficulty and directly obtain the hardness $H$ by $H=P_{\max } / A$, we measured the impression areas $A$ from a large number of AFM images. Fig. 3 displays 
representative AFM micrographs of the indents. In the HPT, HPT+1A, HPT+10A samples, significant material pile-ups around the indents are seen for $\psi \leq 50^{\circ}$, and they become more pronounced for $\psi=35.3^{\circ}$, which is similar to previous reports for other metals and alloys [29,31]. The large pile-up is more obvious in Fig. 4, which shows the AFM images and line scan data across the indents. Such pile-up can induce an overestimation of the calculated $H$ in the O-P method [29,31], and the $\psi$-dependent pile-up complicates the analysis of the relation between $H$ and $\psi$. Such pile-up issue is fully circumvented in the present study since $H$ was obtained directly from the measured $A$.

Fig. 5 summarizes the variations in $H$ as a function of $\psi$ for all four samples. Two features are noteworthy. First, for a given $\psi$, the $H$ value is largely enhanced by the HPT process and further increases upon annealing. Second, for all samples, $H$ varies with reducing $\psi$ (i.e., increasing indentation strain), but the trend is different between as-cast and three HPT processed samples. In the as-cast sample, $H$ increases linearly with decreasing $\psi$. In HPT processed samples, in contrast, $H$ increases until $65.3^{\circ}$ and then decreases for $\psi<65.3^{\circ}$. This variation in $H$ with $\psi$ is related to the constitutive behavior of each material, which is discussed later.

\subsection{Microstructural changes}

To observe the annealing-induced microstructural change, TEM analyses were performed on the HPT and HPT+10A samples. Fig. 6a shows scanning transmission electron microscopy (STEM) image of the HPT sample, which exhibits nc structure with an average grain size $d$ of $\sim 40 \mathrm{~nm}$. To illustrate the chemical composition, EDS elemental mapping was performed for an identical area where the STEM image of Fig. 6a was taken. The EDS maps of the HPT processed sample (Figs. 6b-g) indicate a homogeneous distributions of constituent elements without any clear segregation or clustering. This result is consistent with previous 
atom probe tomography study [14] reporting that the HPT processed CoCrFeMnNi HEA is a single-phase solid solution. Therefore, it is reasonable to conclude that strengthening by HPT in Fig. 5 is mainly due to the grain refinement.

Fig. 7 shows a representative STEM image of HPT+10A sample and the corresponding EDS element maps for the same area. It is seen in Fig. 7a that HEA $+10 \mathrm{~A}$ sample has a slightly larger $d$ than HEA sample but nevertheless it exhibits nc structure with $d$ of $\sim 60 \mathrm{~nm}$. The most noticeable microstructural evolution induced by annealing is the nanoscale chemical decomposition (Figs. 7b-g), that is, the solid solution in the nc HEA becomes unstable and decomposes into multiple phases after $10 \mathrm{~h}$ annealing. As shown in the EDS maps (especially Fig. 7g), three new phases were observed; i.e., a phase rich in $\mathrm{Ni}$ and $\mathrm{Mn}$, a phase only with $\mathrm{Cr}$, and a phase rich in $\mathrm{Fe}$ and $\mathrm{Co}$ (hereafter, to be referred to as $\mathrm{NiMn}, \mathrm{Cr}$, and FeCo phases, respectively). Table 1 summarizes the average chemical compositions that were obtained from more than three EDS point spectra for each phase. These three different phases were also reported for the coarse-grained (cg) CoCrFeMnNi HEA after long-term annealing at $500{ }^{\circ} \mathrm{C}$ for 500 days [18]. The chemical compositions of the phases reported in that study are similar to those in Table 1, and the crystal structures of the new phases were identified as body-centered cubic (bcc) solid solution for the Cr particles, L10 structure for the NiMn phases, and B2 structure for the FeCo phases. Although the particles in Fig. $7 \mathrm{~g}$ seem to be identical to those in the annealed cg HEA [18], there are two major differences. First, in the annealed cg HEA, the new phases preferentially precipitate along the grain boundaries (GBs) that can be energetically preferred nucleation sites for the phases $[32,33]$. In annealed nc HEA of the present study, the new phases have almost the same size as the matrix grain and are random in terms of the location where they precipitated as seen in Fig. 7g. This difference is somewhat expected given the large portion of GBs in nc HEA. Second, for the precipitation of the new phases, the annealing of cg HEA [18] took much longer time 
(500 days) than for the nc HEA in this study. This difference is also rationalized by the large portion of GBs that can enhance the diffusion kinetics. In consideration of these possible reasons for the difference, we conclude that the $\mathrm{Cr}$, NiMn, and FeCo phases observed in this study are the same as those observed previously (i.e., bcc phase, L10 phase, and B2 phase, respectively).

Since the presence of these phases are the main difference in the "observed" microstructure between HPT and HPT+10A samples, one may expect that they play a critical role in the annealing-induced hardening in nc HEA, as suggested earlier by Schuh et al. [14]. As shown in Fig. 7g, the sizes of the new phases are similar to (or even bigger than) $d$ of the matrix phase. Thus, the strengthening mechanism by these new phases is comparable to that seen in composites rather than particle (precipitation) hardening; that is, such phases having intermetallic character (especially, NiMn and FeCo phases) would be much harder than the matrix phase and thus increase the global strength of the nc HEA [14].

\section{Discussion}

\subsection{Constitutive behavior}

As mentioned earlier, plastic flow behavior of the indented samples can be estimated by converting the $H$ vs. $\psi$ data in Fig. 5 into stress vs. strain plots $[23,24,29]$. For this, the following two aspects need recognition. First, the characteristic (or indentation) strain $\varepsilon_{\text {char }}$ underneath a sharp indenter is independent of $h$ due to its geometrical self-similarity. Second, $\varepsilon_{\text {char }}$ of a conical indenter having a half-cone angle $\theta$ is determined as $[24,34]$

$$
\varepsilon_{\text {char }}=0.2 \cdot \tan (\pi-\theta)=0.2 \cdot \cot \theta
$$

For the case that a cone with $\theta$ and a three-sided pyramid with $\psi$ produce the same area-todepth ratio, $\cot \theta$ of Eq. (1) can be obtained as: 


$$
\cot \theta=\left(\sqrt{\frac{3 \sqrt{3}}{\pi} \cdot \tan \psi}\right)^{-1}
$$

which leads to $\varepsilon_{\text {char }}$ for $\psi=85,75,65.3,50$, and $35.3^{\circ}$ as $0.014,0.042,0.072,0.13$, and 0.22 , respectively.

Next, the measured $H$ values can be converted into corresponding flow stresses, $\sigma_{f,}$ by the well known empirical relationship originally suggested by Tabor [35], i.e., $H=C_{\theta} \cdot \sigma_{f}$, where $C_{\theta}$ is the constraint factor. Although $C_{\theta}$ is often considered as 2.7 or 3 for the fully plastic regime of indentation, it would be a strong function of $\psi$ in the elasto-plastic regime [34]. In this regime, Johnson [34] estimated $C_{\theta}$ as

$$
C_{\theta}=\frac{H}{\sigma_{f}}=\frac{2}{3}\left[2+\ln \left(\frac{1}{3} \frac{E \cdot \cot \theta}{\sigma_{y}}\right)\right]
$$

where $E$ is elastic modulus and $\sigma_{\mathrm{y}}$ is yield strength. Note that this equation is based on Johnson's expanding cavity model in which the volume conservation of material (i.e., Poisson's ratio is 0.5) is assumed and flow is assumed to be pressure-insensitive [34]. Eq. (3) shows that $C_{\theta}$ can be determined not only by $\cot \theta$ (of Eq. (2)) but also by material properties such as $E$ and $\sigma_{\mathrm{y}}$. If elastic properties do not vary significantly during the HPT process and subsequent annealing, the value of $E$ of the cg (as-cast) HEA ( 200 GPa [36,37]) can be adopted in Eq. (3) for all nc HEA (HPT, HPT+1A, and HPT+10A) samples. However, information about the variation in $\sigma_{\mathrm{y}}$ during HPT process and subsequent annealing is still required for estimating the $C_{\theta}$ of $\mathrm{HPT}, \mathrm{HPT}+1 \mathrm{~A}$, and $\mathrm{HPT}+10 \mathrm{~A}$ samples by Eq. (3). While the $\sigma_{\mathrm{y}}$ for cg (as-cast) and nc (HPT) samples has been well documented ( $0.2 \mathrm{GPa}[38]$ and $\sim 1.4 \mathrm{GPa}[14,19]$, respectively), the $\sigma_{\mathrm{y}}$ for annealed nc samples are unknown. Therefore, we attempted to estimate $\sigma_{\mathrm{y}}$ of all samples by using the nanoindentation data. Since $\psi=85^{\circ}$ can apply substantially low $h_{\mathrm{f}} / h_{\max }$ (especially for nc samples) and $\varepsilon_{\text {char }}(\sim 0.014)$, it is reasonable 
to assume that the corresponding $\sigma_{\mathrm{r}}$ is close to $\sigma_{\mathrm{y}}$. Thus, by substituting $H$ and $\theta$ values for $\psi$ $=85^{\circ}$ into Eq. (3), the middle term of it becomes $H / \sigma_{\mathrm{y}}$, which then can be written as:

$$
\frac{H}{\sigma_{y}}=\frac{2}{3}\left[2+\ln \left(\frac{1}{3} \frac{E \cdot \cot \theta}{\sigma_{y}}\right)\right] \quad\left(\text { for } \psi=85^{\circ}\right) .
$$

Here, the elastic properties of all samples in the right-hand term are those of the as-cast sample (as mentioned above), and $H$ of each sample in the left-hand term can be directly obtained from nanoindentation tests with $\psi=85^{\circ}$. To determine the $\sigma_{\mathrm{y}}$ values for each specimen by solving Eq. (4), an arbitrary value of $\sigma_{\mathrm{y}}$ was put into both the left- and righthand term. Then, it was varied until the value of the left- and right-hand terms became the same, at which the corresponding $\sigma_{\mathrm{y}}$ was determined as the $\sigma_{\mathrm{y}}$ of each sample. Fig. 8 shows this procedure and the results obtained; i.e., $\sigma_{\mathrm{y}}$ for as-cast, HPT, HPT+1A, and HPT+10A were determined as $\sim 0.4, \sim 1.6, \sim 2.3$, and $\sim 3.3 \mathrm{GPa}$, respectively. The values of $\sigma_{\mathrm{y}}$ for as-cast and HPT samples estimated from Eq. (4) are in a good agreement with the literature data [14,19,38] (in consideration of indentation size effect, ISE [39], that can explain the small discrepancy), which implies that the estimated $\sigma_{\mathrm{y}}$ of HPT+1A and HPT+10A samples may also be reasonable.

With the estimated $\sigma_{\mathrm{y}}$, values of $C_{\theta}$ for each condition can be determined by using Eq. (3), and are summarized in Table 2. Based on the assumption that the elastic-plastic regime ends and a fully plastic regime begins at $C_{\theta}=3$ [34], if the calculated $C_{\theta}$ is higher than 3 , we adopted $C_{\theta}=3$ instead of the calculated value in Table 2 . With these values of $C_{\theta}$, now $H$ can be converted into $\sigma_{f}$. The variations in $\sigma_{f}$ with $\varepsilon_{\text {char }}$ for all samples are plotted in Fig. 9, where the tensile test data for the as-cast HEA obtained by $\mathrm{Wu}$ et al. [38] is also shown for comparison purposes. In the case of the as-cast sample, although there is a slight difference in stress (possibly due to the ISE [39] that is not considered in the procedure we have used here), 
the estimated stress-strain relation and its hardening behavior are in reasonably good agreement with the results from tensile testing. By extension, the estimated stress-strain relations of the three nc HEAs (HPT, HPT+1A, and HPT+10A) in Fig. 9 can be considered representative.

\subsection{Strain softening and its possible mechanisms}

In Fig. 9, all nc HEA samples (HPT, HPT+1A, and HPT+10A) exhibit strain softening behavior, which is opposite to the work hardening of the cg (as-cast) sample. Strain softening phenomena have been frequently observed in tensile and compressive tests of nc and ultrafine-grained (ufg) metals and alloys [40-43]. Recently, this softening behavior was also reported for HPT processed nc CoCuFeNi HEA [16]. For conventional nc metals, a variety of possible mechanisms such as extensive dynamic recovery $[44,45]$, dynamic recrystallization [46-48], and the existence of residual internal stress in GBs [49] have been proposed to explain this softening behavior, although there remains controversy over the mechanism. In the case of nc HEA, which mechanism is the most predominant for the strain softening is unclear as yet and requires further analysis in the future, but it is anticipated that similar mechanisms to those for conventional nc metals may still be valid.

The most interesting feature related with strain softening in Fig. 9 is that the softening behavior becomes more pronounced as the annealing time increases, i.e., the HPT $+10 \mathrm{~A}$ sample exhibits the largest amount of softening whereas the HPT sample shows the smallest one. This indicates that in comparison of only HPT processed sample (which may be governed by proposed softening mechanisms of other nc metals and alloys [44-49]), an additional mechanism may be at work in the strain softening of annealed HPT samples. To gain insights into the possible additional mechanism of annealed HPT samples, the change in microstructure of annealed HPT sample with the applied $\varepsilon_{\text {char }}$ was investigated. Figs. 10a and 
10b show the microstructures of HPT+10A sample underneath the indentation produced with Berkovich $\left(\psi=65.3^{\circ}\right)$ and cube-corner tip $\left(\psi=35.3^{\circ}\right)$, respectively. The subsurface regions also exhibit the annealing-induced precipitates ( $\mathrm{Cr}$, NiMn, and $\mathrm{FeCo}$ ) as observed in the undeformed region of Fig. 7g. The volume fraction of each phase is listed in Table 3. The fraction of the precipitates was reduced by almost one-half as $\varepsilon_{\text {char }}$ increases from 0.08 (Berkovich) to 0.22 (cube-corner), which implies that the second phases were dissolved due to the extensive plastic deformation. This led us to the conclusion that more pronounced strain softening behavior in annealed nc HEA sample may be attributed to the deformation assisted dissolution of the precipitates. It is noteworthy that some extent of indenter tip bluntness is observed for the cube-corner indentations (Fig. 10b). This tip bluntness is inevitable in a sharp indenter, since imperfections are created during indenter production and, more importantly, the indenter is progressively worn out as it is used [50]. Although the tip bluntness may affect the measured results (especially for a shallow-depth indentation), such influence was not significant here due to the large indentation depth $\left(h_{\max } \sim 2000 \mathrm{~nm}\right.$ for cubecorner indenter, see Fig. 2a).

The deformation-induced dissolution of a second phase has been reported in many metallic systems and was frequently explained by recourse to the thermodynamics of the metastable phases [51-58] according to which, plastic deformation could lead to the destabilization of second phases. To evaluate the thermodynamic stability of the intermetallic NiMn and FeCo phases in the annealed HEA at room temperature, the "stress-independent" activation energy for the dissolution, $\Delta G_{\mathrm{diss}, 0}\left(=\Delta G_{\mathrm{HEA}}-\Delta G_{\mathrm{int}}\right)$, was calculated. The Gibbs free energy for the formation of HEA, $\Delta G \mathrm{HEA}$, is given as

$$
\Delta G_{\mathrm{HEA}}=\Delta H_{\mathrm{HEA}}-T \Delta S_{\mathrm{HEA}}
$$

where $\Delta H$ and $\Delta S$ are the enthalpy and entropy of mixing respectively, and $T$ is the absolute temperature. For the HEA examined in this study, the values of $\Delta H_{\text {HEA }}$ and $\Delta S_{\text {HEA }}$ are $\sim-4.8$ 
$\mathrm{kJ} / \mathrm{mol}$ and $\sim 13.4 \mathrm{~J} / \mathrm{mol} \cdot \mathrm{K}$, respectively [1]. Then, at $T=298 \mathrm{~K}$, Eq. (5) yields $\Delta G_{\mathrm{HEA}}$ as -8.8 $\mathrm{kJ} / \mathrm{mol}$. Similarly, the value of the Gibbs free energy for the formation of intermetallic phase, $\Delta G_{\text {int, }}$ can be calculated. Since its mixing entropy $\Delta S_{\text {int }}$ can be assumed as 0 for ordered intermetallics, $\Delta G_{\text {int }}$ becomes the same as the mixing enthalpy $\Delta H_{\text {int }}$ [59]. The values of $\Delta H_{\text {int }}$ for NiMn and FeCo intermetallics are reported as -12.2 [59,60] and $-10.1 \mathrm{~kJ} / \mathrm{mol}[61]$, respectively, which are adopted as $\Delta G_{\text {int }}$ in this study. With these values, $\Delta G_{\text {diss }, 0}$ values for NiMn phase and FeCo phase are determined as $\sim 3.4$ and $\sim 1.3 \mathrm{~kJ} / \mathrm{mol}$, respectively, which are within the range reported for the activation barrier for solid state transformation (0.3-3 $\mathrm{kJ} / \mathrm{mol}[58,62])$ including martensitic transformation that also can be induced by plastic deformation. Furthermore, Languillaume et al. [51] calculated the value of $\Delta G_{\text {diss }, 0}$ for cementite in pearlitic steel as $\sim 15 \mathrm{~kJ} / \mathrm{mol}$, and reported that (at least partial) dissolution of cementite occurred during cold wire drawing. All these observations suggest that the dissolution of the secondary intermetallic phases in the HEA can occur at room temperature, and it may become easier during plastic deformation.

It was often suggested that the deformation assisted destabilization of intermetallic particles is attributed to the increasing matrix-particle interface energy due to the dislocation accumulation during plastic deformation [51-53,56,63]. It is apparent from Eq. (1) and Fig. $2 \mathrm{~b}$ that a sharper indenter imposes a higher level of plastic deformation, and thus induces higher interface energy. Especially, the contribution of interface energy to the particle dissolution is more pronounced for a harder phase, since the density of geometrically necessary dislocations (GNDs) near the interface between soft matrix and hard phase is dependent on strain gradients across the interface [64-66]. This scenario is consistent with the experimental results that the dissolutions of NiMn and FeCo phases are more pronounced than that of $\mathrm{Cr}$ phase (see Fig. 10 and Table 3). For nc metals, however, the capacity of dislocation accumulation is not expected to be sufficiently high due to their extremely small 
grain size $[10,11,67]$. Therefore, in this study, deformation assisted dissolution cannot be exclusively explained only by dislocations accumulation at the matrix/particle interfaces.

Another contribution to the dissolution can be envisaged by considering the friction at the matrix-particle interface. Ivanisenko et al. [54] proposed that the flow of a soft matrix around harder particles can impose high strain energy on the interface due to the friction at the interface. In this regard, the friction at the interface during nanoindentation may play a role for increasing interface energy, and it will be enhanced for a sharper indentation.

In addition, in order for the thermodynamic non-equilibrium of secondary phases to be a driving force for their dissolution, a substantial atomic diffusion should occur during the deformation. In the present case, the high fraction of GBs in annealed nc HEA can become channels for migration of atoms. Note that the large pressure gradient underneath the indenter can significantly increase the diffusivity $[68,69]$. In this respect, the larger pressure gradient underneath a sharper indenter may further enhance the diffusivity, resulting in the promotion of the second phase dissolution. However, additional experiments and simulations are required to provide a full picture of the deformation assisted particle dissolution mechanism in annealed nc HEAs.

\section{Conclusion}

In the present study, annealing effects on the stress-strain behavior of HPT processed CoCrFeMnNi HEAs were systematically investigated through nanoindentation experiments with five different three-sided pyramidal indenters. Nanohardness measurements show that the hardness of nc HEA increases further upon annealing at $450{ }^{\circ} \mathrm{C}$. The annealing-induced hardening is mainly due to the formation of a nanostructured multiphase microstructure, consisting of NiMn-, FeCo-, and Cr-rich phases embedded in the matrix. By using the concepts of characteristic strain and constraint factor, the strain-dependent plastic flow of nc 
HEAs was successfully obtained from hardness vs. indenter angle data. Considerable strain softening was revealed in nc HEA samples, which became pronounced as annealing time increasesed. In the TEM analysis, the volume fractions of NiMn- and FeCo-rich intermetallic phases were reduced by almost one-half as indentation strain increased from 0.08 to 0.22 , suggesting that the deformation assisted dissolution of the precipitates may be the reason for the additional strain softening in annealed nc HEA. The deformation assisted destabilization of precipitates can be rationalized in consideration of the increase in the interface energy, which in turn can be explained by recourse to the dislocation accumulation and friction at the matrix/particle interfaces.

\section{Acknowledgements}

The work at Hanyang University was supported by the National Research Foundation of Korea (NRF) grants funded by the Ministry of Science and ICT (No. 2015R1A5A1037627 and No. 2017R1A2B4012255). JYS would like to thank the support from the Convergence Agenda Program (CAP) of the Korea Research Council of Fundamental Science and Technology (CAP-11-05-KRISS).

\section{References}

1. Y. Zhang, T.T. Zuo, Z. Tang, M.C. Gao, K.A. Dahmen, P.K. Liaw, Z.P. Lu, Microstructures and properties of high-entropy alloys, Prog. Mater. Sci. 61 (2014) 193.

2. D.B. Miracle, O.N. Senkov, A critical review of high entropy alloys and related concepts, Acta Mater. 122 (2017) 448-511.

3. F. Otto, A. Dlouhý, C. Somsen, H. Bei, G. Eggeler, E.P. George, The influences of temperature and microstructure on the tensile properties of a $\mathrm{CoCrFeMnNi}$ highentropy alloy, Acta Mater. 61 (2013) 5743-5755.

4. B. Gludovatz, A. Hohenwarter, D.Catoor, E.H. Chang, E.P. George, R.O. Ritchie, A fracture-resistant high-entropy alloy for cryogenic applications, Science 345 (2014) 1153-1158.

5. Y. Zhao, D.-H. Lee, M.-Y. Seok, J.-A Lee, M.P. Phaniraj, J.-Y. Suh, H.-Y. Ha, J.-Y. Kim, U. Ramamurty, J.-i. Jang, Resistance of CoCrFeMnNi high-entropy alloy to gaseous hydrogen embrittlement, Scripta Mater. 135 (2017) 54-58.

6. R.Z. Valiev and T.G. Langdon, Principles of equal-channel angular pressing as a processing tool for grain refinement, Prog. Mater. Sci. 51 (2006) 881-981. 
7. A.P. Zhilyaev and T.G. Langdon, Using high-pressure torsion for metal processing: Fundamentals and applications, Prog. Mater. Sci. 53 (2008) 893-979.

8. H. Gleiter, Nanocrystalline materials, Prog. Mater. Sci. 33 (1989) 223-315.

9. R. Valiev, Nanostructuring of metals by severe plastic deformation for advanced properties, Nat. Mater. 3 (2004) 511-516.

10. M.A. Meyers, A. Mishra, D.J. Benson, Mechanical properties of nanocrystalline materials, Prog. Mater. Sci. 51 (2006) 427-556.

11. M. Dao, L. Lu, R.J. Asaro. J.T.M. De Hosson, E. Ma, Toward a quantitative understanding of mechanical behavior of nanocrystalline metals, Acta Mater. 55 (2007) 4041-4065.

12. T. Zhu, J. Li, Ultra-strength materials, Prog. Mater. Sci. 55 (2010) 710-757.

13. D.-H. Lee, I.-C. Chi, M.-Y. Seok, J. He, Z. Lu, J.-Y. Suh, M. Kawasaki, T.G. Langdon, J.-i. Jang, Nanomechanical behavior and structural stability of a nanocrystalline CoCrFeNiMn high-entropy alloy processed by high-pressure torsion, J. Mater. Res. 30 (2015) 2804-2815.

14. B. Schuh, F.M. Martin, B. Völker, E.P. George, H. Clemens, R. Pippan, A. Hohenwarter, Mechanical properties, microstructure and thermal stability of a nanocrystalline $\mathrm{CoCrFeMnNi}$ high-entropy alloy after severe plastic deformation, Acta Mater. 96 (2015) 258-268.

15. D.-H. Lee, M.-Y. Seok, Y. Zhao, I.-C. Choi, J. He, Z. Lu, J.-Y. Suh, U. Ramamurty, M. Kawasaki, T.G. Langdon, J.-i. Jang, Spherical nanoindentation creep behavior of nanocrystalline and coarse-grained $\mathrm{CoCrFeMnNi}$ high-entropy alloys, Acta Mater. 109 (2016) 314-322.

16. R. Zheng, J. Chen, W. Xiao, C. Ma, Microstructure and tensile properties of nanocrystalline $(\mathrm{FeNiCoCu})_{1-\mathrm{x}} \mathrm{Ti}_{\mathrm{x}} \mathrm{Al}_{\mathrm{x}}$ high entropy alloys processed by high pressure torsion, Intermetallics 74 (2016) 38-45.

17. E.J. Pickering, R. Muñoz-Moreno, H.J. Stone, N.G. Jones, Precipitation in the equiatomic high-entropy alloy CrMnfeCoNi, Scripta Mater. 113 (2016) 106-109.

18. F. Otto, A. Dlouhý, K.G. Pradeep, M. Kuběnová, D. Raabe, G. Eggeler, E.P. George, Decomposition of the single-phase high-entropy alloy $\mathrm{CrMnFeCoNi}$ after prolonged anneals at intermediate temperatures, Acta Mater. 112 (2016) 40-52.

19. H. Shahmir, J. He, Z. Lu, M. Kawasaki, T.G. Langdon, Effect of annealing on mechanical properties of a nanocrystalline CoCrFeNiMn high-entropy alloy processed by high-pressure torsion, Mater. Sci. Eng. A 676 (2016) 294-303.

20. Q.H. Tang, Y. Huang, Y.Y. Huang, X.Z. Liao, T.G. Langdon, P.Q. Dai, Hardening of an $\mathrm{A} 10.3 \mathrm{CoCrFeNi}$ high entropy alloy via high-pressure torsion and thermal annealing, Mater. Lett. 151 (2015) 126-129.

21. W.C. Oliver, G.M. Pharr, An improved technique for determining hardness and elastic modulus using load and displacement sensing indentation experiments, J. Mater. Res. 7 (1992) 1564-1583.

22. A. Gouldstone, N. Chollacoop, M. Dao, J. Li, A.M. Minor, Y.-L. Shen, Indentation across size scales and disciplines: Recent developments in experimentation and modeling, Aca Mater. 55 (2007) 4015-4039.

23. S. Shim, J.-i. Jang, G. M. Pharr, Extraction of flow properties of single crystal silicon carbide by nanoindentation and finite element simulation, Acta Mater. 56 (2008) 3824-3832.

24. U. Ramamurty, J.-i. Jang, Nanoindentation for probing the mechanical behavior of molecular crystals-a review of the technique and how to use it, Cryst. Eng. Comm. 16 (2014) 12-23.

25. M.-Y. Seok, Y.-J. Kim, I.-C. Choi, Y. Zhao, J.-i. Jang, Predicting flow curves of two- 
phase steels from spherical nanoindentation data of constituent phases: Isostrain method vs. non-isostrain method, Int. J. Plast. 59 (2014) 108-118.

26. M.-Y. Seok, J.-A Lee, D.-H. Lee, U. Ramamurty, S. Nambu, T. Koseki, J.-i. Jang, Decoupling the contributions of constituent layers to the strength and ductility of a multi-layered steel, Acta Mater. 121 (2016) 164-172.

27. V. Maier-Kiener, B. Schuh, E.P. George, H. Clemens, A. Hohenwarter, Nanoindentation testing as a powerful screening tool for assessing phase stability of nanocrystalline high-entropy alloys, Mater. Lett. 115 (2017) 479-485.

28. J.-i. Jang, M.J. Lance, S. Wen, T.Y. Tsui, G.M. Pharr, Indentation-induced phase transformations in silicon: influences of load, rate, and indenter angle on the transformation behavior, Acta Mater. 53 (2005) 1759-1770.

29. I.-C. Choi, Y.-J. Kim, Y.M. Wang, U. Ramamurty, J.-i. Jang, Nanoindentation behavior of nanotwinned $\mathrm{Cu}$ : Influences of indenter angle on hardness, strain rate sensitivity and activation volume, Acta Mater. 61 (2013) 7313-7323.

30. D.-H. Lee, J.-A Lee, M.-Y. Seok, U.B. Baek, S.H. Nahm, J.-i. Jang, Stress-dependent hardening-to-softening transition of hydrogen effects in nanoindentation of a linepipe steel, Int. J. Hydrogen Energy 39 (2014) 1897-1902.

31. J.H. Strader, S. Shim, H. Bei, W.C. Oliver, G.M. Pharr, An experimental evaluation of the constant $\beta$ relating the contact stiffness to the contact area in nanoindentation, Philos. Mag. 86 (2006) 5285-5298.

32. A. Hohenwarter, M. Faller, B. Rashkova, R. Pippan, Influence of heat treatment on the microstructural evolution of $\mathrm{Al}-3 \mathrm{wt} . \% \mathrm{Cu}$ during high-pressure torsion, Philos. Mag. Lett. 94 (2014) 342-350.

33. B.B. Straumal, B. Baretzky, A.A. Mazilkin, F. Phillipp, O.A. Kogtenkova, M.N. Volkov, R.Z. Valiev, Formation of nanograined structure and decomposition of supersaturated solid solution during high pressure torsion of $\mathrm{Al}-\mathrm{Zn}$ and $\mathrm{Al}-\mathrm{Mg}$ alloys, Acta Mater. 52 (2004) 4469-4478.

34. K. L. Johnson, Contact mechanics. Cambridge: Cambridge University Press, 1985.

35. D. Tabor, The hardness of metals. Oxford: Oxford University Press 1951.

36. Z. Wu, H. Bei, G.M. Pharr, E.P. George, Temperature dependence of the mechanical properties of equiatomic solid solution alloys with face-centered cubic crystal structures, Acta Mater. 81 (2014) 428-441.

37. C. Zhu, Z.P. Lu, T.G. Nieh, Incipient plasticity and dislocation nucleation of FeCoCrNiMn high-entropy alloy, Acta Mater. 61 (2013) 2993-3001.

38. Y. Wu, W.H. Liu, X.L. Wang, D. Ma, A.D. Stoica, T.G. Nieh, Z.B. He, Z.P. Lu, In-situ neutron diffraction study of deformation behavior of a multi-component high-entropy alloy, Appl. Phys. Lett. 104 (2014) 051910.

39. W.D. Nix, H. Gao, Indentation size effects in crystalline materials: A law for strain gradient plasticity, J. Mech. Phys. Solids 46 (1998) 411-425.

40. Y. Champion, C. Langlois, S. Guérin-Mailly, P. Langlois, J.L. Bonnentien, M.J. Hytch, Near-perfect elastoplasticity in pure nanocrystalline copper, Science 300 (2003) 310-311.

41. D. Jia, K.T. Ramesh, E. Ma, Effects of nanocrystalline and ultrafine grain sizes on constitutive behavior and shear bands in iron, Acta Mater. 51 (2003) 3495-3509.

42. C.Y. Yu, P.L. Sun, P.W. Kao, C.P. Chang, Mechanical properties of submicron-grained aluminum, Scripta Mater. 52 (2005) 359-363.

43. A. Khalajhedayati, T.J. Rupert, Emergence of localized plasticity and failure through shear banding during microcompression of a nanocrystalline alloy, Acta Mater. 65 (2014) 326-337.

44. S. Hariprasad, S.M.L. Sastry, K.L. Jerina, Deformation behavior of a rapidly 
solidified fine grained Al-8.5\%Fe-1.2\%V-1.7\%Si alloy, Acta Mater. 44 (1996) 383389.

45. F.H. Dalla Torre, R. Lapovok, J. Sandlin, P.F. Thomson, C.H.J. Davies, E.V. Pereloma, Microstructures and properties of copper processed by equal channel angular extrusion for 1-16 passes, Acta Mater. 52 (2004) 4819-4832.

46. M.H. Shih, C.Y. Yu, P.W. Kao, C.P. Chang, Microstructure and flow stress of copper deformed to large plastic strains, Scripta Mater. 45 (2001) 793-799.

47. J.-C. Lee, J.-Y. Suh, J.-P. Ahn, Work-softening behavior of the ultrafine-grained Al alloy processed by high-strain-rate, dissimilar-channel angular pressing, Metall. Mater. Trans. A 34 (2003) 625-632.

48. W. Wei, K.X. Wei, G.J. Fan, A new constitutive equation for strain hardening and softening of fcc metals during severe plastic deformation, Acta Mater. 56 (2008) 4771-4779.

49. F. Tang, J.M. Schoenung, Strain softening in nanocrystalline or ultrafine-grained metals: A mechanistic explanation, Mater. Sci. Eng. A 493 (2008) 101-103.

50. A.C. Fischer-Cripps, The sharpness of Berkovich indenter, J. Mater. Res., 25 (2010) 927-934.

51. J. Languillaume, G. Kapelski, B. Baudelet, Cementite dissolution in heavily cold drawn pearlitic steel wires, Acta Mater. 45 (1997) 1201-1212.

52. A.Y. Badmos, H.K.D.H. Bhadeshia, The evolution of solutions: A thermodynamic analysis of mechanical alloying, Metall. Mater. Trans. A 28A (1997) 2189-2194.

53. C. Suryanarayana, Mechanical alloying and milling, Prog. Mater. Sci. 46 (2001) 1184.

54. Y. Ivanisenko, W. Lojkowsk, R.Z. Valiev, H.-J. Fecht, The mechanism of formation of nanostructure and dissolution of cementite in a pearlitic steel during high pressure torsion, Acta Mater. 51 (2003) 5555-5570.

55. Z. Horita, K. Ohashi, T. Fujita, K. Kaneko, T.G. Langdon, Achieving high strength and high ductility in precipitation-hardened alloys, Adv. Mater. 17 (2005) 1599-1602.

56. Z. Liu, S. Bai, X. Zhou, Y. Gu, On strain-induced dissolution of $\theta^{\prime}$ and $\theta$ particles in Al-Cu binary alloy during equal channel angular pressing, Mater. Sci. Eng. A 528 (2011) 2217-2222.

57. M. Song, K. Du, Z.Y. Huang, H. Huang, Z.R. Nie, H.Q. Ye, Deformation-induced dissolution and growth of precipitates in an $\mathrm{Al}-\mathrm{Mg}-\mathrm{Er}$ alloy during high-cycle fatigue, Acta Mater. 81 (2014) 409-419.

58. J.D. Embury, A. Deschamps, Y. Brechet, The interaction of plasticity and diffusion controlled precipitation reactions, Scripta Mater. 49 (2003) 927-932.

59. D.M.J. King, S.C. Middleburgh, A.G. McGregor, M.B. Cortie, Predicting the formation and stability of single phase high-entropy alloys, Acta Mater. 104 (2016) 172-179.

60. A.R. Miedema, The electronegativity parameter for transition metals: Heat of formation and charge transfer in alloys, J. Less-Common Met. 41 (1973) 117-136.

61. I. Ohnuma, H. Enoki, Osamu Ikeda, R. Kainuma, H. Ohtani, B. Sundman, K. Ishida, Phase equilibria in the Fe-Co binary system, Acta Mater. 50 (2002) 379-393.

62. J.W. Martin, R.D. Doherty, B. Cantor, Stability of microstructure in metallic systems. Cambridge University Press 1997.

63. J. Weissmüller, J.W. Cahn, Mean stresses in microstructures due to interface stresses: A generalization of a capillary equation for solids, Acta Mater. 45 (1997) 1899-1906.

64. A. Ramazani, K. Mukherjee, A. Schwedt, P. Goravanchi, U. Prahl, W. Bleck, Quantification of the effect of transformation-induced geometrically necessary dislocations on the flow-curve modelling of dual-phase steels, Int. J. Plast. 43 (2013) 
128-152.

65. R.I. Barabash, O.M. Barabash, M. Ojima, Z. Yu, J. Inoue, S. Nambu, T. Koseki, R. $\mathrm{Xu}, \mathrm{Z}$. Feng, Interphase strain gradients in multilayered steel composite from microdiffraction, Metall. Mater. Trans. A 45A (2014) 98-108.

66. G. Langford, Deformation of pearlite, Metall. Trans. A 8A (1977) 861-875.

67. K.M. Youssef, R.O. Scattergood, K.L. Murty, J.A. Horton, C.C. Koch, Ultrahigh strength and high ductility of bulk nanocrystalline copper, Appl. Phys. Lett. 87 (2005) 091904.

68. Y.L. Chiu, A.H.W. Ngan, Time-dependent characteristics of incipient plasticity in nanoindentation of a Ni3Al single crystal, Acta Mater. 50 (2002) 1599-1611.

69. P.C. Wo, A.H.W. Ngan, Incipient plasticity during nano-scratch in Ni3Al, Philos. Mag. 84 (2004) 3145-3157. 


\section{List of Tables and Figures}

Table 1 Chemical compositions (at.\%) of the phases existing in undeformed HPT+10A sample.

Table 2 Calculated constrain factor $\left(C_{\theta}\right)$ values.

Table 3 Volume fractions of NiMn, FeCo and $\mathrm{Cr}$ phases underneath the indenter in HPT+10A sample.

Fig. 1 Typical microstructures of (a) as-cast and (b) HPT processed CoCrFeMnNi HEA.

Fig. 2 Results of the nanoindentation experiments with indenters having various angles: (a) Typical load-displacement curves for HPT processed samples (with inset image showing the curves for as-cast sample); (b) variations in the ratio of the final depth to maximum displacement as a function of indenter angle.

Fig. 3 Representative AFM micrographs of hardness impressions; (a-e) for as-cast; (f-j) for HPT; (k-o) for HPT+1A; (p-t) for HPT+10A.

Fig. 4 Representative examples of AFM images and surface profile data for cube-corner indentations.

Fig. 5 Variations in nanoindentation hardness $H$ as a function of indenter angle $\psi$.

Fig. 6 STEM image and corresponding elemental distribution maps of only HPT processed sample.

Fig. 7 STEM image and corresponding elemental distribution maps of HPT+10A sample.

Fig. 8 An example presenting how to determine the yield strength and the obtained results for each sample. 
Fig. 9 Estimated stress-strain relations derived from nanoindentation data.

Fig. 10 Cross-sectional TEM micrographs and corresponding EDS maps for the subsurface region underneath the indenter (for $\mathrm{HPT}+10 \mathrm{~A}$ ): (a) Berkovich and (b) cube-corner indenter. 
Table 1 Chemical compositions (at.\%) of the phases existing in undeformed HPT+10A sample.

\begin{tabular}{c|ccccc}
\hline \hline Phase & $\begin{array}{c}\mathrm{Co} \\
\text { [at.\%] }\end{array}$ & $\begin{array}{c}\mathrm{Cr} \\
\text { [at.\%] }\end{array}$ & $\begin{array}{c}\mathrm{Fe} \\
\text { [at.\%] }\end{array}$ & $\begin{array}{c}\mathrm{Mn} \\
\text { [at.\%] }\end{array}$ & $\begin{array}{c}\mathrm{Ni} \\
\text { [at.\%] }\end{array}$ \\
\hline NiMn & $4.7 \pm 1.1$ & $2.3 \pm 1.8$ & $2.3 \pm 1.4$ & $40.6 \pm 2.0$ & $50.0 \pm 2.3$ \\
$\mathrm{Cr}$ & $4.3 \pm 0.9$ & $81.2 \pm 3.2$ & $8.2 \pm 0.3$ & $4.3 \pm 0.8$ & $2.0 \pm 1.7$ \\
$\mathrm{FeCo}$ & $41.6 \pm 3.0$ & $1.8 \pm 0.8$ & $41.1 \pm 3.6$ & $9.0 \pm 2.4$ & $6.6 \pm 4.1$ \\
\hline \hline
\end{tabular}


Table 2 Calculated constrain factor $\left(C_{\theta}\right)$ values.

\begin{tabular}{cccccc}
\hline \hline & $\psi=85^{\circ}$ & $\psi=75^{\circ}$ & $\psi=65.3^{\circ}$ & $\psi=50^{\circ}$ & $\psi=35.3^{\circ}$ \\
\hline \hline As-cast & 2.9 & 3.6 & 4.0 & 4.4 & 4.7 \\
HPT & 2.0 & 2.8 & 3.1 & 3.5 & 3.9 \\
HPT+1A & 1.8 & 2.5 & 2.9 & 3.3 & 3.6 \\
HPT+10A & 1.5 & 2.3 & 2.6 & 3.0 & 3.4 \\
\hline \hline
\end{tabular}


Table 3 Volume fractions of NiMn, FeCo and Cr phases underneath the indenter in HPT+10A sample.

\begin{tabular}{c||c|c|c}
\hline \hline \multicolumn{1}{c||}{} & \multicolumn{3}{c}{ Volume fraction (\%) } \\
\cline { 2 - 4 } & NiMn & FeCo & $\mathrm{Cr}$ \\
\hline $\begin{array}{c}\psi=65.3^{\circ} \\
(\varepsilon \sim 0.08)\end{array}$ & 20.4 & 13.3 & 10.2 \\
\hline $\begin{array}{c}\psi=35.3^{\circ} \\
(\varepsilon \sim 0.22)\end{array}$ & 12.5 & 7.1 & 8.4 \\
\hline \hline
\end{tabular}


(a)

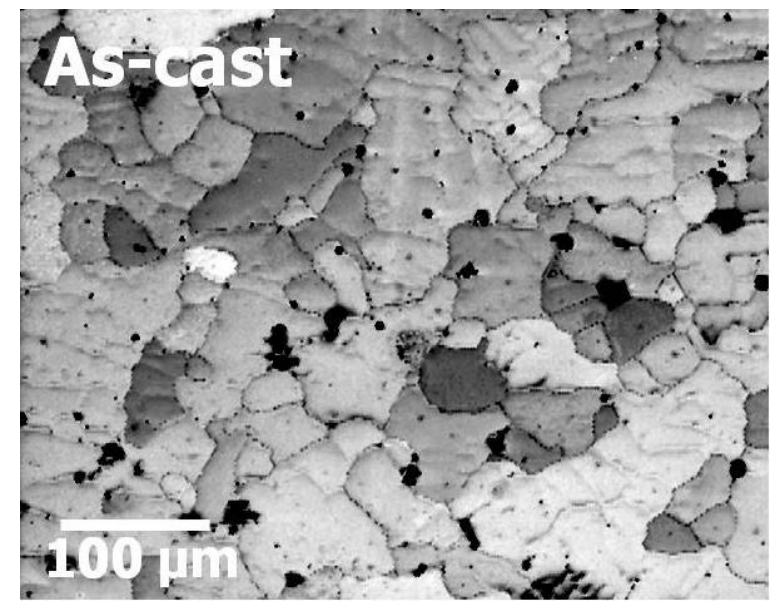

(b)

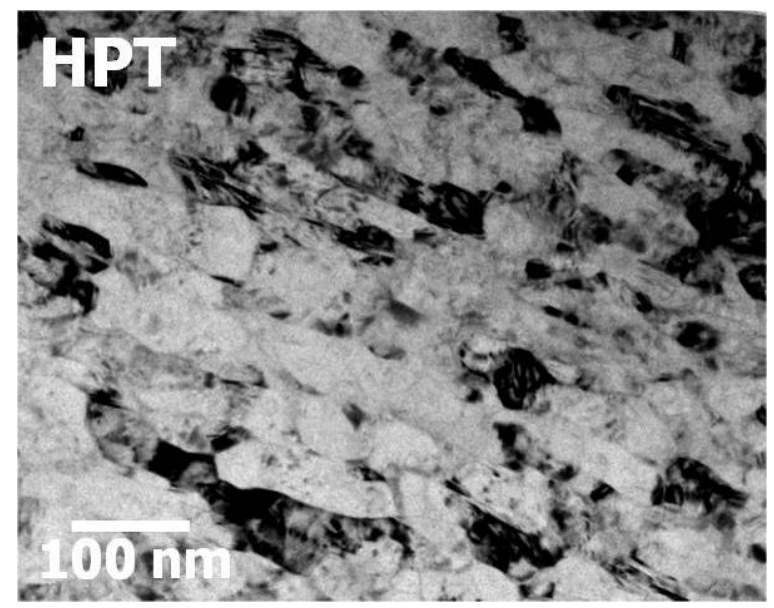

Fig. 1 Typical microstructures of (a) as-cast and (b) HPT processed CoCrFeMnNi HEA. 

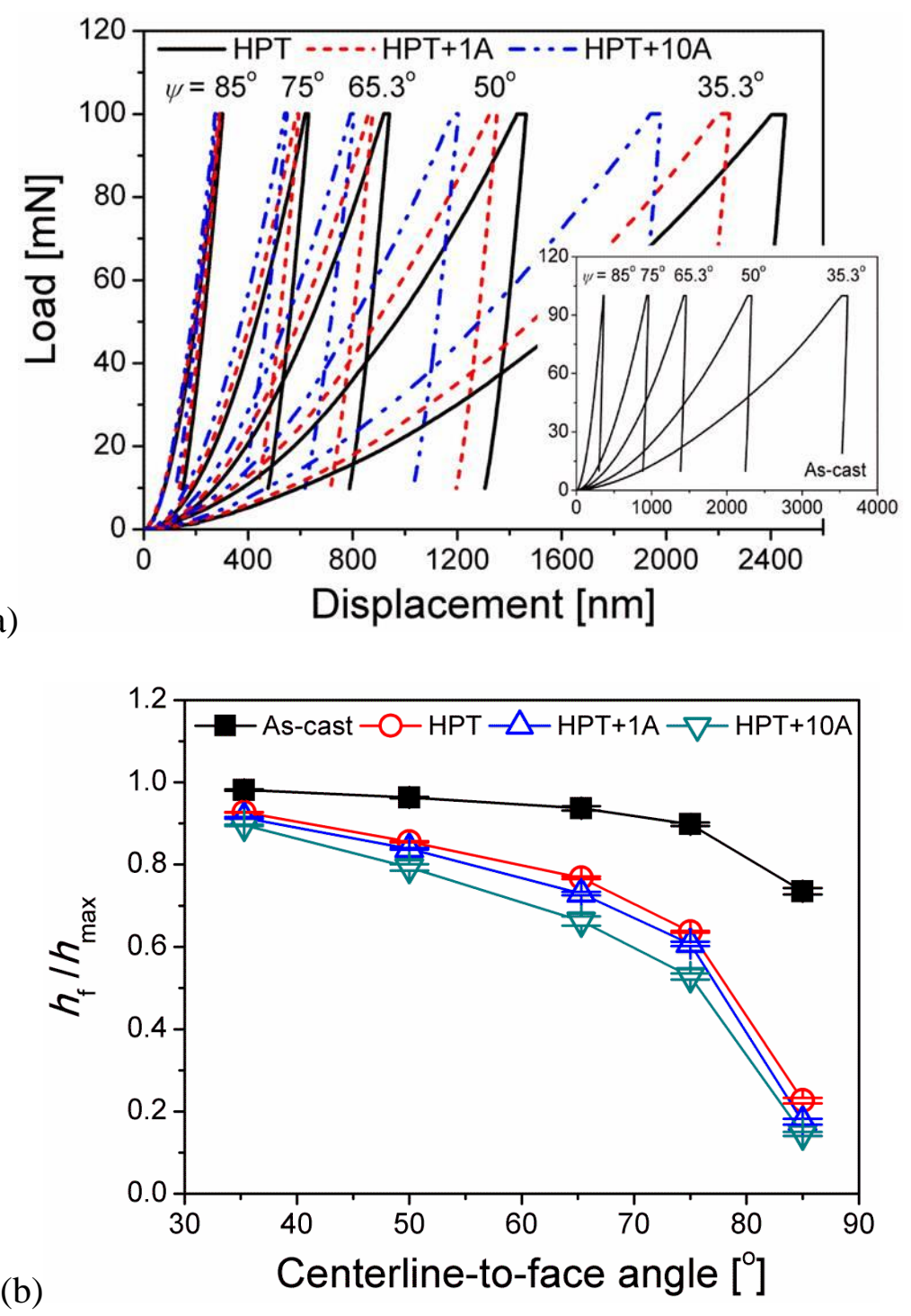

Fig. 2 Results of the nanoindentation experiments with indenters having various angles: (a)

Typical load-displacement curves for HPT processed samples (with inset image showing the curves for as-cast sample); (b) variations in the ratio of the final depth to maximum displacement as a function of indenter angle. 


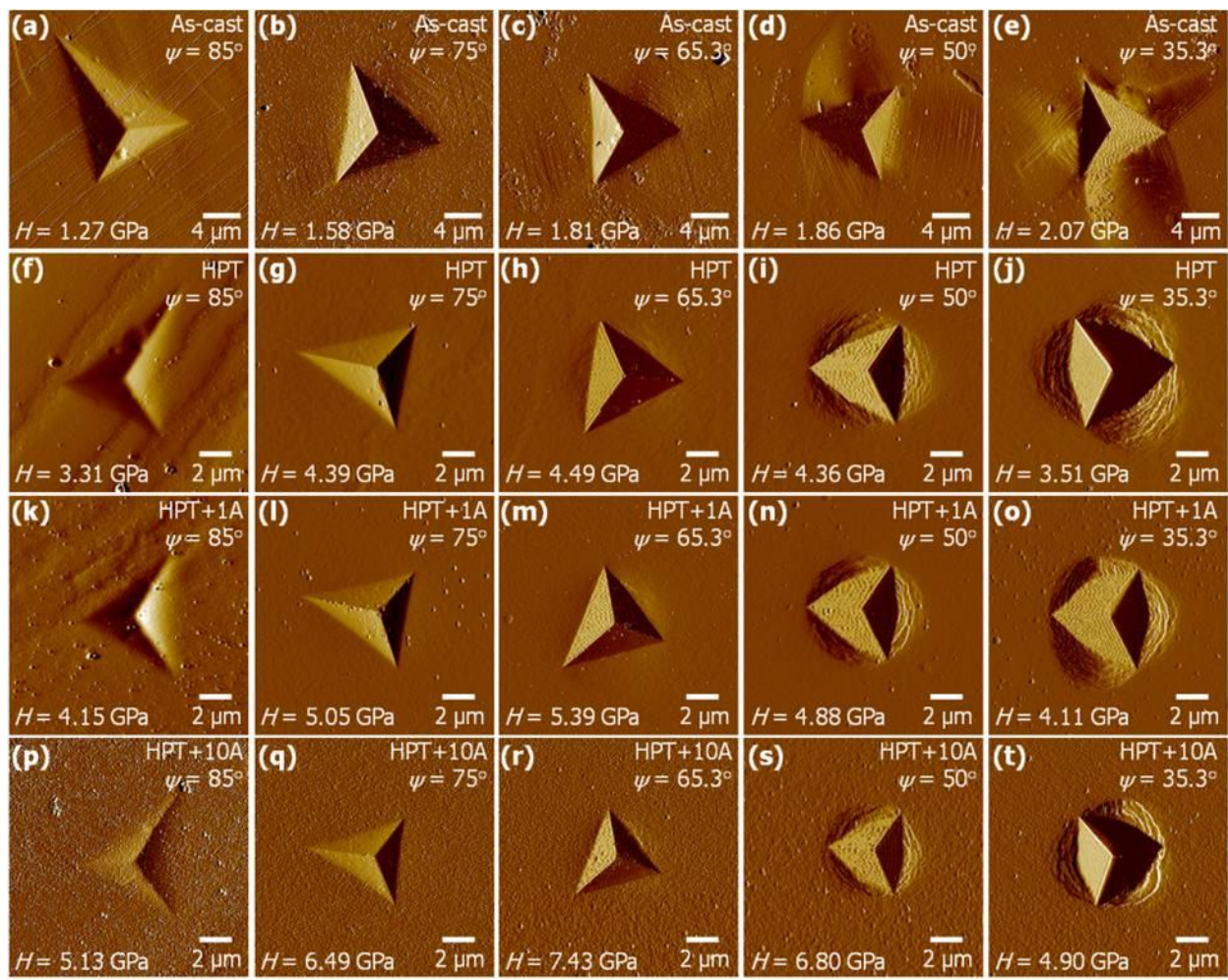

Fig. 3 Representative AFM micrographs of hardness impressions; (a-e) for as-cast; (f-j) for HPT; (k-o) for HPT+1A; $(p-t)$ for HPT+10A. 


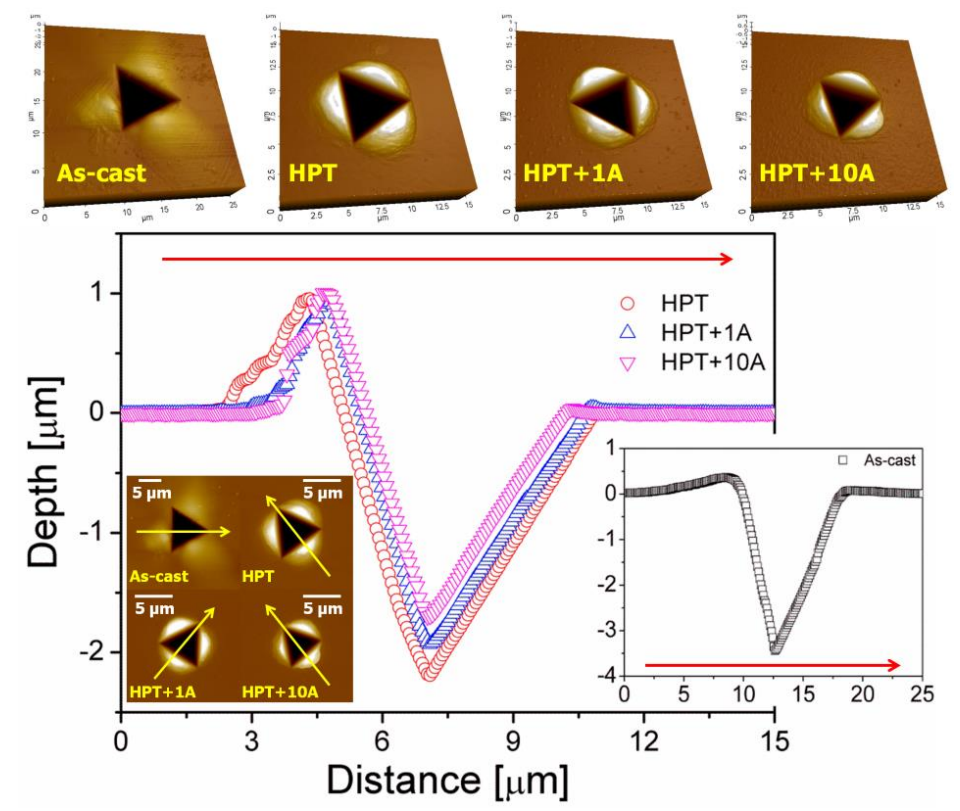

Fig. 4 Representative examples of AFM images and surface profile data for cube-corner indentations. 


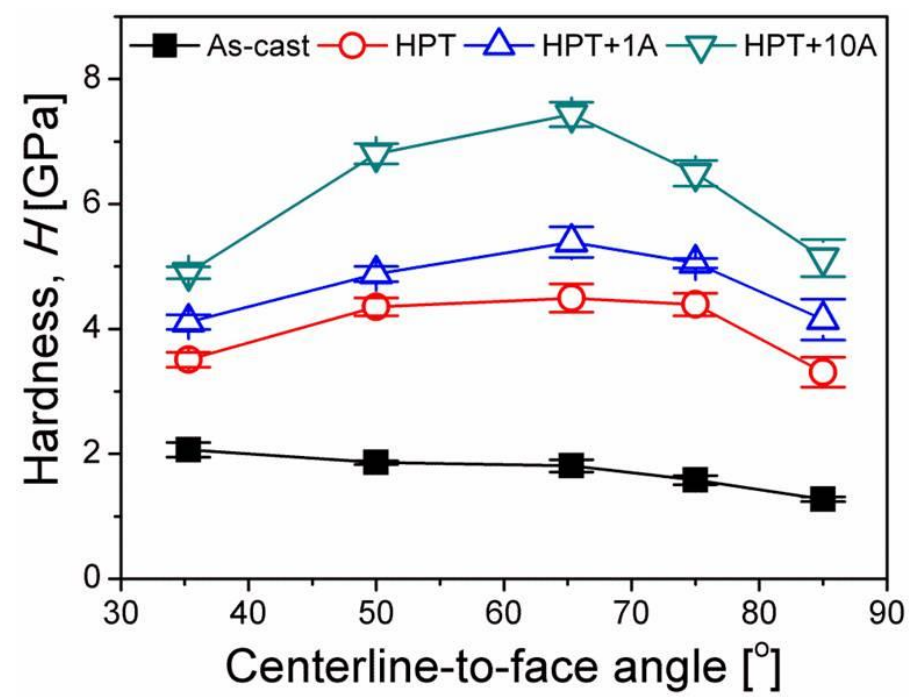

Fig. 5 Variations in nanoindentation hardness $H$ as a function of indenter angle $\psi$. 


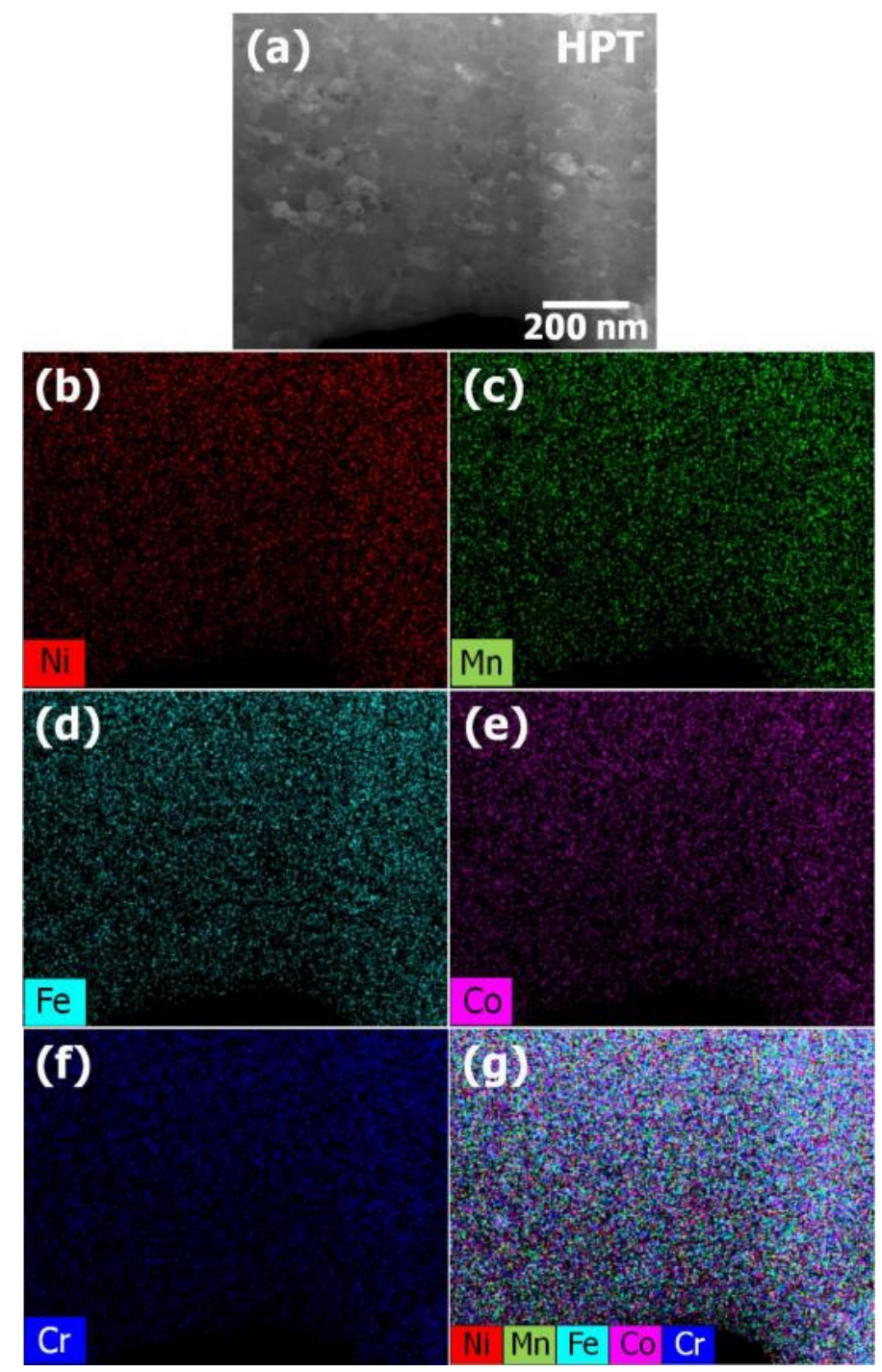

Fig. 6 STEM image and corresponding elemental distribution maps of only HPT processed sample. 


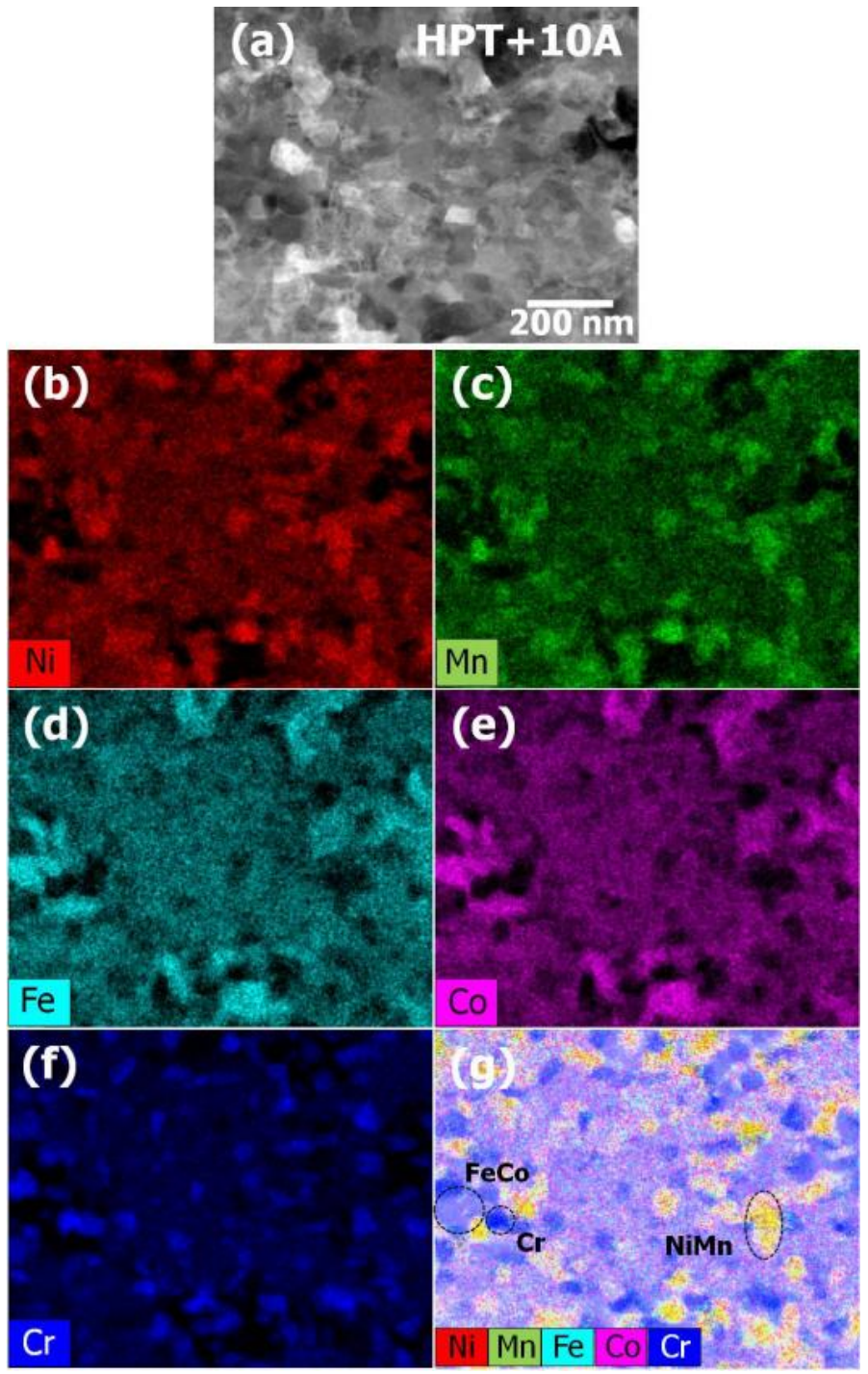

Fig. 7 STEM image and corresponding elemental distribution maps of HPT+10A sample. 


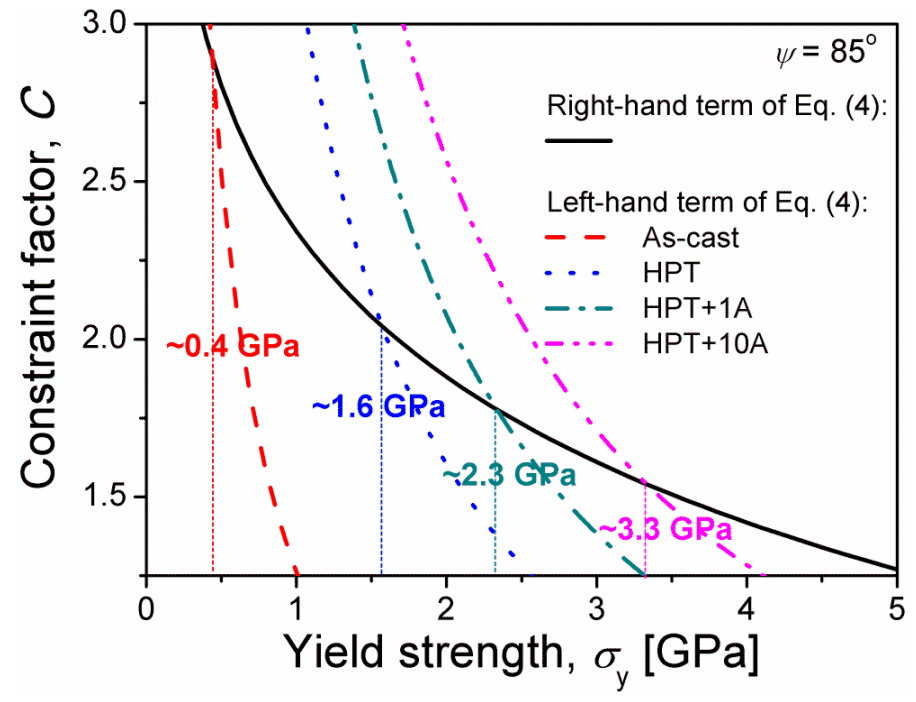

Fig. 8 An example presenting how to determine the yield strength and the obtained results for each sample. 


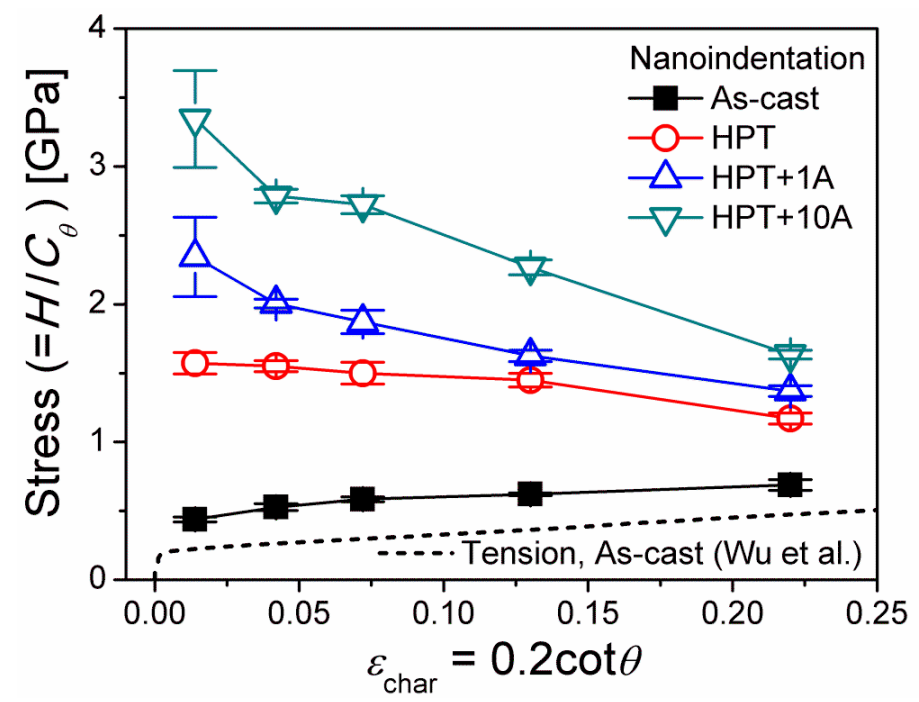

Fig. 9 Estimated stress-strain relations derived from nanoindentation data. 


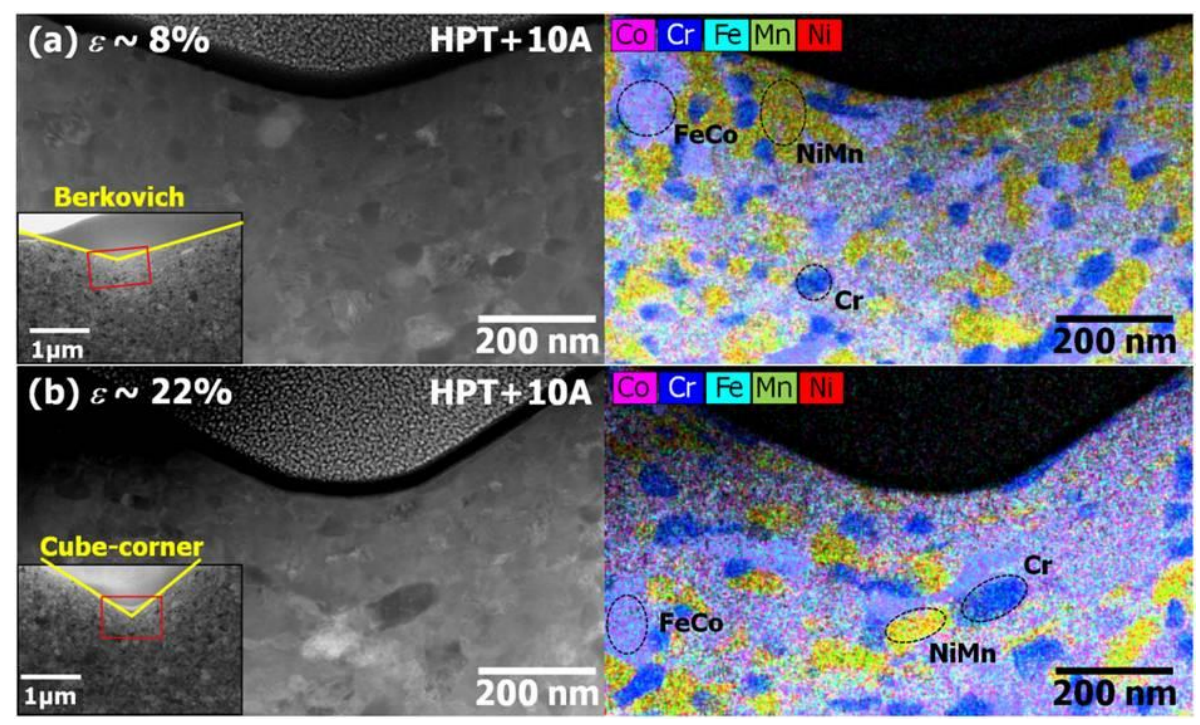

Fig. 10 Cross-sectional TEM micrographs and corresponding EDS maps for the subsurface region underneath the indenter (for HPT+10A): (a) Berkovich and (b) cube-corner indenter. 